\title{
In Planta Dynamic Analysis of Onion Yellows Phytoplasma Using Localized Inoculation by Insect Transmission
}

\author{
Wei Wei, Shigeyuki Kakizawa, Shiho Suzuki, Hee-Young Jung, Hisashi Nishigawa, \\ Shin-ichi Miyata,Kenro Oshima, Masashi Ugaki, Tadaaki Hibi, and Shigetou Namba
}

First, eighth, ninth, and tenth authors: Laboratory of Plant Pathology, Graduate School of Agricultural and Life Sciences, The University of
Tokyo, 1-1-1 Yayoi, Bunkyo-ku, Tokyo 113-8657, Japan; and second, third, fourth, fifth, sixth, seventh, eighth, and tenth authors:
Laboratory of Bioresource Technology, Graduate School of Frontier Sciences, The University of Tokyo, 202-Bioscience Building, 5-1-5
Kashiwanoha, Kashiwa, Chiba 277-8562, Japan. Accepted for publication 28 October 2003.

\begin{abstract}
Wei, W., Kakizawa, S., Suzuki, S., Jung, H.-Y., Nishigawa, H., Miyata, S., Oshima, K., Ugaki, M., Hibi, T., and Namba, S. 2004. In planta dynamic analysis of onion yellows phytoplasma using localized inoculation by insect transmission. Phytopathology 94:244-250.

Due to the lack of a means to inoculate plants mechanically, the histological dynamics and in planta spread of phytoplasmas have been studied very little. We analyzed the dynamics of plant infection by phytoplasmas, using a technique to infect a limited area of a leaf, nested polymerase chain reaction (PCR), real-time PCR, and immunohistochemical visualization. Following localized inoculation of a leaf of garland chrysanthe-

mum (Chrysanthemum coronarium) by the vector leafhopper Macrosteles striifrons, the onion yellows (OY) phytoplasma spread within the plant from the inoculated leaf to the main stem (1 day postinoculation [dpi]), to the roots and the top leaf ( $2 \mathrm{dpi})$, and to other leaves from top to bottom (from 7 to $21 \mathrm{dpi}$ ). The populations of the OY phytoplasmas in inoculated leaves and roots increased approximately sixfold each week from 14 to $28 \mathrm{dpi}$. At $14 \mathrm{dpi}$, the OY phytoplasmas colonized limited regions of the phloem tissue in both the root and stem and then spread throughout the phloem by 21 dpi. This information should form the basis for elucidating the mechanisms of phytoplasma multiplication and migration within a plant host.
\end{abstract}

Plant-pathogenic phytoplasmas are cell wall-less prokaryotic organisms in the class Mollicutes. Phytoplasmas parasitize the phloem tissues of infected plant hosts and are transmitted by insect vectors (mostly leafhoppers) $(7,10)$. Although phytoplasmas are important plant pathogens causing more than 700 diseases in several hundred plant species, their biological and phytopathological characterization has been hindered by the fact that they are obligatory endocellular organisms, not culturable on artificial media and cannot be transmitted mechanically $(7,10)$.

Several studies have examined localization and migration of phytoplasmas within infected plant tissues. The colonization of peach and chokecherry by the western X phytoplasma, and apple and pear by the apple proliferation and pear decline phytoplasmas, respectively, was visualized by staining phytoplasma DNA with 4',6-diamidino-2-phenylindole $(2,18,19)$. The distribution of clover phyllody phytoplasma was analyzed in the leaves, petals, sepals, receptacles, and pedicels of strawberry plants using an enzyme-linked immunosorbent assay (ELISA) (1). In addition, the migration of western $\mathrm{X}$, western aster yellows, and other phytoplasmas in graft-inoculated periwinkle and their host plants has been reported $(6,8)$. Despite effective inoculation and detection techniques, the dynamics of phytoplasmas in their host plants remain poorly understood.

To analyze in planta population dynamics and the spread of phytoplasmas, we utilized localized inoculation by insect trans-

Corresponding author: S. Namba; E-mail address: snamba@ims.u-tokyo.ac.jp

Publication no. P-2004-0120-01R

(C) 2004 The American Phytopathological Society mission, nested polymerase chain reaction (PCR) for sensitive detection, real-time PCR for quantification, and immunohistochemical visualization for localization.

\section{MATERIALS AND METHODS}

Phytoplasma and plant materials. Onion yellows (OY) phytoplasma was obtained in Saga Prefecture, Japan, in May 1982 (11) and was subsequently maintained in garland chrysanthemum (Chrysanthemum coronarium) plants using a leafhopper vector, Macrosteles striifrons. The leafhoppers used to inoculate OY phytoplasma fed on OY-infected plants for more than 40 days. OY phytoplasma belongs to the aster yellows (AY) $16 \mathrm{~S}$ group and induces a variety of symptoms in host plants, including virescence, yellowing, phyllody, stunting, and proliferation $(11,16)$

Localized inoculation and sampling. In garland chrysanthemum plants at the eight-leaf stage ( $\approx 30$ days after germination), the third or fourth leaf was located approximately in the middle of the plant and was about $10 \times 5 \mathrm{~cm}$ in size. This leaf was covered with cling film, and a window $(5-\times 5-\mathrm{mm})$ was opened just above the midrib of the leaf to allow leafhoppers to feed. The leaf covered with film was then enclosed in a mesh sack and an inoculative leafhopper was released into the sack and removed 2 days later.

Tissues from the garland chrysanthemum plants inoculated using the localized inoculation method described previously were collected from 1 day to 4 weeks postinoculation. Seven plants were used at each sampling date. Root, main stem, apical meristem area, inoculated leaf, lower leaves, and upper leaves were sampled for nested PCR, real-time PCR, and immuno- 
histochemical analysis. Garland chrysanthemum plants infected with OY phytoplasma and showing typical symptoms and healthy garland chrysanthemums that noninfected leafhoppers had fed on were used as positive and negative controls, respectively. The plants were grown at $25^{\circ} \mathrm{C}$ in a greenhouse with a 16-h light/8-h dark photoperiod until they were used for analysis.

Extraction and detection of phytoplasma DNA by nested PCR. Total DNA from plant samples was extracted according to the procedure described by Namba et al. (13). A universal primer set, SN910601/SN011119 (4), and a phytoplasma-specific primer set, SN920204/SN910502 (13), were used for the first and second steps of nested PCR assays, respectively. The PCR was performed as described by Schaff et al. (17). The reaction mixture was as follows: $1 \mu \mathrm{l}(100 \mathrm{ng})$ of total DNA, $200 \mu \mathrm{M}$ dNTPs, 0.4 to $1.0 \mu \mathrm{M}$ primers, $10 \times$ buffer, and Taq DNA polymerase (Takara Shuzo, Japan) in a volume of $25 \mu$ l. The following conditions were performed for 35 cycles on a thermal cycler (PE9700; Applied Biosystems, Japan): $1 \mathrm{~min}$ at $94^{\circ} \mathrm{C}, 2 \mathrm{~min}$ at $50^{\circ} \mathrm{C}$, and $3 \mathrm{~min}$ at $72^{\circ} \mathrm{C}$. The second PCR reaction was performed under the same conditions after dilution 1:50 in distilled water.

Detection of phytoplasma DNA by real-time PCR. The tuf gene-specific primer set Tuf1 (5'-GCTAA AACTT GTCCA CGTTG TACG-3')/Tuf2 (5'-CGGAA ATAGA ATTGA GGACG GT-3') and a fluorogenic TaqMan probe (5'-TGTTT TAACT AAAAG AAGAA GGAGG ACGTC ACACT GCCTT TTTCT CTC-3') were designed from partial sequences of the $t u f$ gene of OY phytoplasma (12). Real-time quantitative PCR was performed using a Smart Cycler (Cepheid, Sunnyvale, CA) with the following reaction mixture: $5 \mu \mathrm{M}$ each primer, $4 \mathrm{mM} \mathrm{MgCl}$, and $2 \mu \mathrm{l}$ of template DNA in a total volume of $25 \mu$. The reaction was carried out for up to 40 cycles using the following conditions: $15 \mathrm{~s}$ at $95^{\circ} \mathrm{C}, 20 \mathrm{~s}$ at $55^{\circ} \mathrm{C}$, and $60 \mathrm{~s}$ at $72^{\circ} \mathrm{C}$. The results were analyzed using Smart Cycler Software (Cepheid).

Immunohistochemical analysis. Part of the secA gene (GenBank Accession No. AB056578) of OY phytoplasma fused to a $6 \times$ histidine tag was expressed in Escherichia coli. Immunoglobulin $\mathrm{G}$ (IgG) was prepared from antibody against this fusion protein (anti-SecA IgG) as described previously (5). Using anti-SecA IgG, immunohistochemical analysis was carried out according to the procedure described by Oshima et al. (15). Approximately 2-cm long pieces of root, main shoot, and apical meristem area were excised from infected garland chrysan-

TABLE 1. Detection of onion yellows phytoplasmas by nested polymerase chain reaction in various parts of the inoculated garland chrysanthemums at various time postinoculation ${ }^{\mathrm{a}}$

\begin{tabular}{lccccccc}
\hline & \multicolumn{7}{c}{ Days postinoculation } \\
\cline { 2 - 7 } Plant part & 1 & 2 & 4 & 7 & 14 & 21 & 28 \\
\hline SAA & 4 & 5 & 6 & 7 & 7 & 7 & 7 \\
MS & 4 & 5 & 7 & 7 & 7 & 7 & 7 \\
UL9 & $\ldots$ & $\ldots$ & $\ldots$ & $\ldots$ & $\ldots$ & $\ldots$ & 7 \\
UL8 & $\ldots$ & $\ldots$ & $\ldots$ & $\ldots$ & $\ldots$ & $\ldots$ & 7 \\
UL7 & $\ldots$ & $\ldots$ & $\ldots$ & $\ldots$ & $\ldots$ & 7 & 7 \\
UL6 & $\ldots$ & $\ldots$ & $\ldots$ & $\ldots$ & 7 & 7 & 7 \\
UL5 & $\ldots$ & $\ldots$ & $\ldots$ & 6 & 7 & 7 & 7 \\
UL4 & 1 & 4 & 5 & 5 & 6 & 7 & 6 \\
UL3 & 0 & 1 & 1 & 2 & 6 & 6 & 7 \\
UL2 & 0 & 0 & 0 & 2 & 3 & 7 & 7 \\
UL1 & 0 & 0 & 0 & 0 & 1 & 7 & 6 \\
IL & 7 & 7 & 7 & 7 & 7 & 7 & 7 \\
LL & 0 & 0 & 1 & 0 & 3 & 6 & 7 \\
R & 0 & 4 & 6 & 7 & 7 & 7 & 7 \\
\hline
\end{tabular}

${ }^{\text {a }} \mathrm{SAA}=$ shoot apical area, $\mathrm{MS}=$ main stem, $\mathrm{UL}=$ upper leaves (the italicized leaf number is counted from the inoculated leaf), $\mathrm{IL}=$ inoculated leaf, $\mathrm{LL}=$ lower leaves, and $\mathrm{R}=$ root.

b Number of phytoplasma-positive plants among seven test plants. themum plants at 1, 2, 4, 7, 14, 21, and 28 days postinoculation (dpi), fixed, embedded in paraffin, and sectioned to $8 \mu \mathrm{m}$ thicknesses with a microtome (PR-50; Yamato Scientific, Japan). Anti-SecA IgG was used with an alkaline phosphatase-mediated reporter system to detect OY phytoplasma in each tissue.

\section{RESULTS}

Nested PCR. Nested PCR is very sensitive for the detection of phytoplasmas, even in asymptomatic latently infected host plants
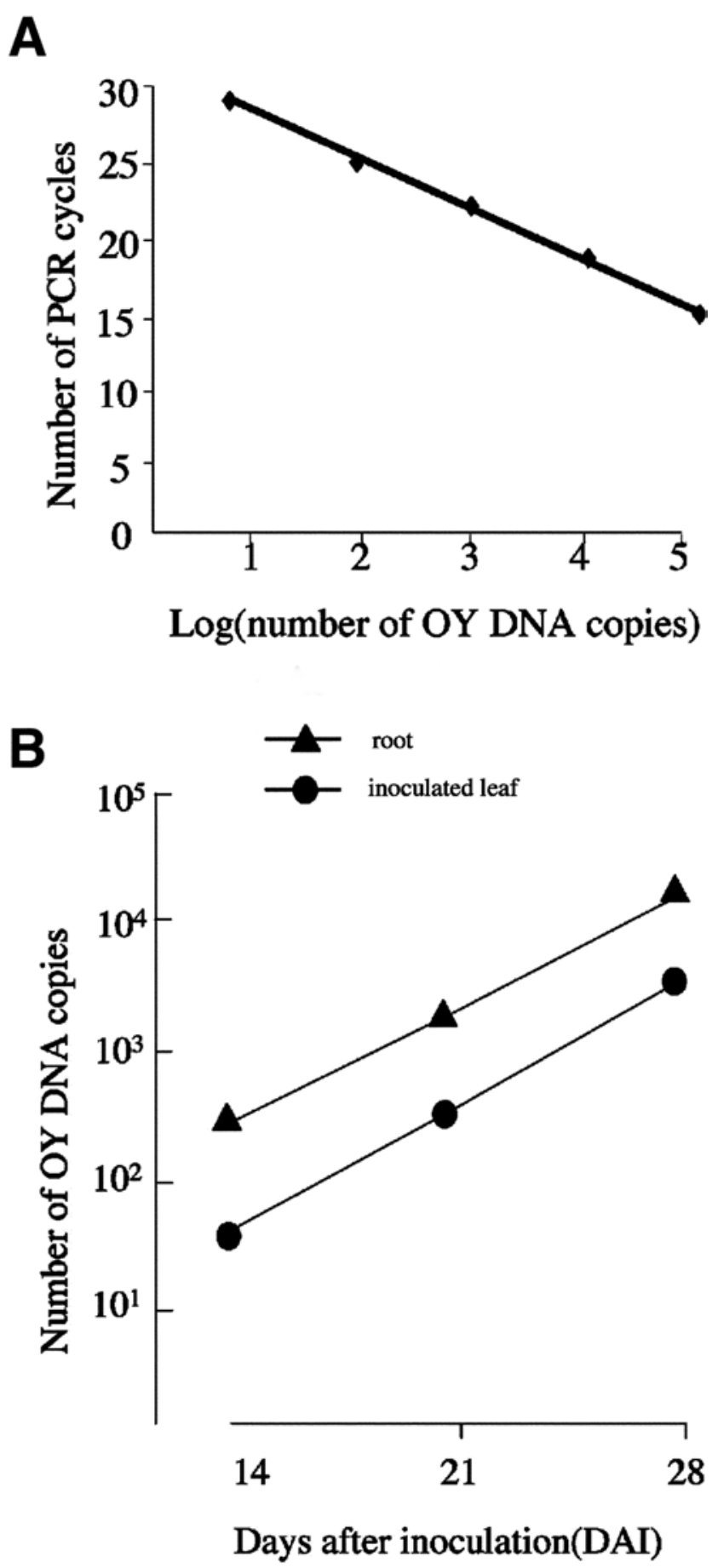

Fig. 1. A, Standard curve used to quantify onion yellows (OY) phytoplasma by real-time polymerase chain reaction (PCR) obtained using serially diluted total OY phytoplasma DNA. B, Quantitative analysis of OY phytoplasma using real-time PCR from 14 to 28 days postinoculation. 
(22). We used nested PCR to investigate the multiplication and migration of OY phytoplasma in infected host plants. OY phytoplasma was detected after $1 \mathrm{dpi}$ in both the inoculated leaf and the main stem including the shoot apical area (Table 1). At 2 dpi, OY phytoplasma was detected in the root and top most leaf of the plant. Until $4 \mathrm{dpi}$, no new leaves developed beyond the four leaves above the inoculated leaf that were already set on the day of inoculation. Subsequently, new leaves started to develop sequentially at a rate of one leaf per week like those of healthy plants, but infected plants grew shorter than healthy ones. OY phytoplasma was detected in all of these newly emerged leaves. At 21 and $28 \mathrm{dpi}$, OY phytoplasma was detected in all of the plant parts examined.
Real-time PCR. To quantify the multiplication of the OY phytoplasma in infected plant tissues, real-time PCR was performed with a TaqMan probe. The intensity of fluorescence was monitored by fluorescence-based quantification during PCR by the hydrolysis of an internal fluorogenic probe; a technique that has been used to quantify small amounts of DNA (3). Calibration using known amounts of serially diluted total DNA of OY phytoplasma gave a linear curve, assuring the reliability of our phytoplasma quantification method (Fig. 1A). Samples of inoculated leaf and root tissues collected from each inoculated plant at 1, 2, $4,7,14,21$, and 28 dpi were subjected to total DNA extraction and the real-time PCR assay. OY phytoplasma was not detected until 7 dpi. The quantity of phytoplasma genomic DNA was
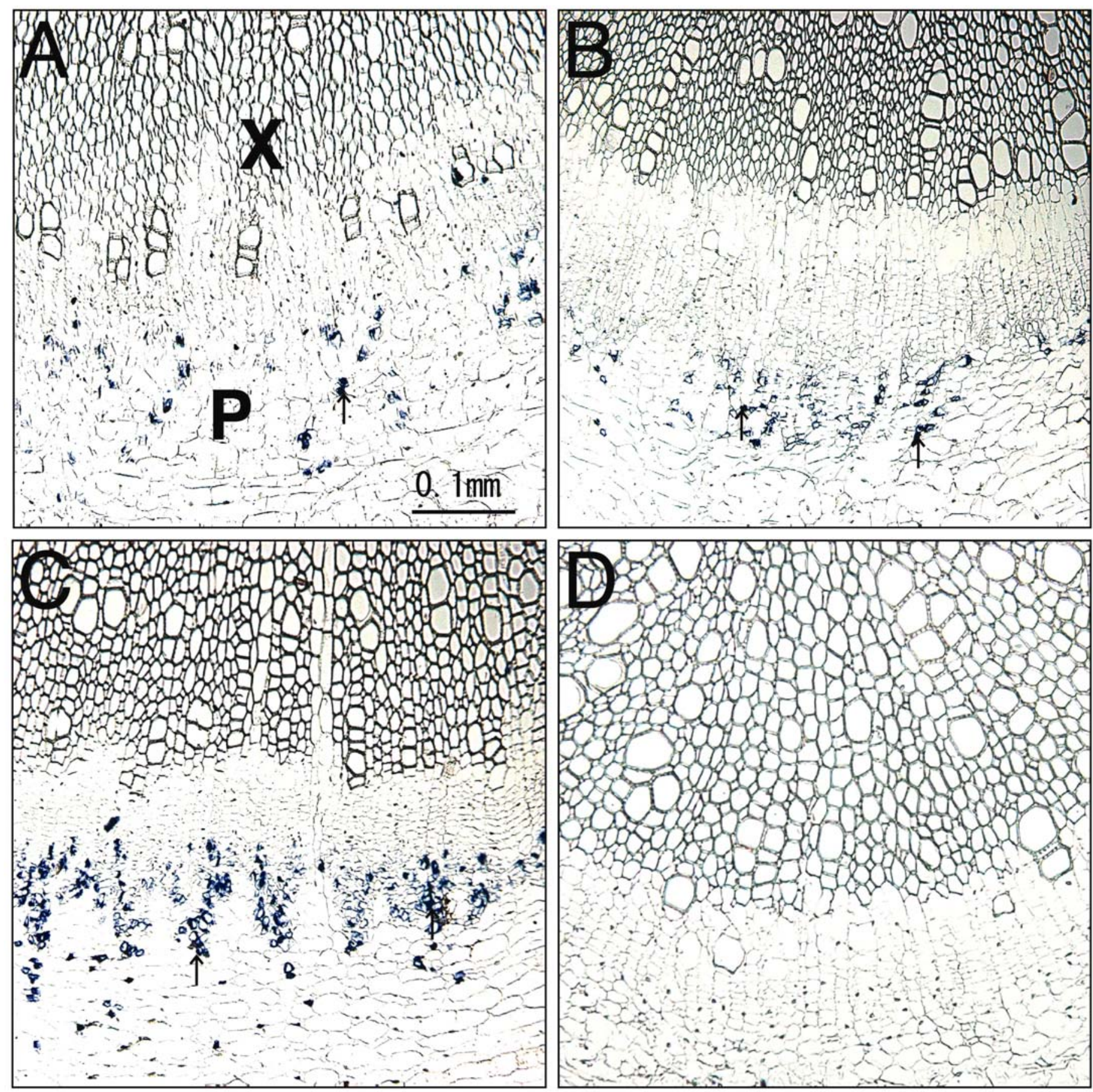

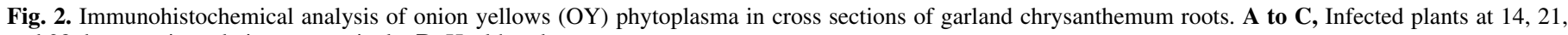
and 28 days postinoculation, respectively. D, Healthy plant. 


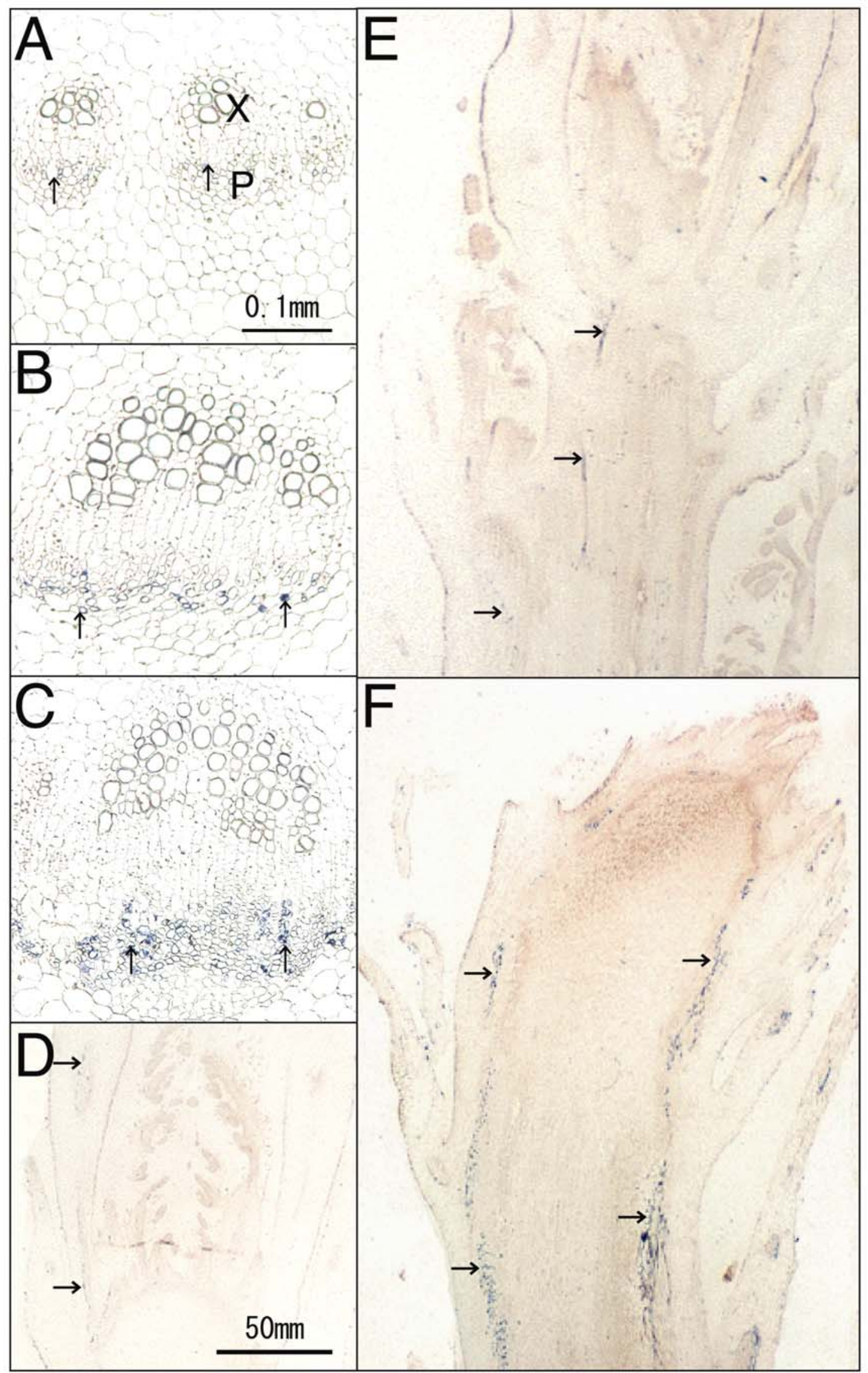

Fig. 3. Immunohistochemical analysis of onion yellows (OY) phytoplasma in cross sections of the main stem (MS) and longitudinal sections of the shoot apical area (SAA) of inoculated garland chrysanthemum. A to C, MS at 14, 21, and 28 days postinoculation (dpi); D to F, SAA at 14, 21 , and 28 dpi. 
estimated at $4.90 \times 10^{3}(14 \mathrm{dpi}), 2.87 \times 10^{4}(21 \mathrm{dpi})$, and $1.74 \times$ $10^{5}$ (28 dpi) copies per gram of root samples and $4.30 \times 10^{2}$ (14 dpi), $2.53 \times 10^{3}(21 \mathrm{dpi})$, and $1.56 \times 10^{4}(28 \mathrm{dpi})$ copies per gram of inoculated leaf samples (Fig. 1B). The copy number of OY phytoplasma genome DNA increased approximately sixfold per week. Similar results were obtained in samples from the main stem, shoot apical region, and top leaf of the plant, whereas phytoplasma was detected in other leaves until 4 weeks after inoculation and was most abundant in the inoculated leaf and in the top leaf, second most abundant in the second youngest leaf, and less abundant in sequentially lower leaves (data not shown).

Immunohistochemical analysis. To observe the detailed localization of OY phytoplasma in various tissues from inoculated plants, the root, main stem, and shoot apical region were sampled and subjected to immunohistochemical analysis. Blue signals indicating the presence of OY phytoplasma were detected by optical microscopy in cross sections from the root at 14,21 , and 28 dpi (Fig. 2A to C), whereas no signal was seen in the root sections at 1, 2, 4, and 7 dpi (data not shown). When the samples obtained at 14 dpi were observed closely, the blue signals were localized to the phloem (Fig. 2A). Then, the signal spread throughout the phloem in OY-infected roots (Fig. 2B) and was strongest at 28 dpi (Fig. 2C). Cross sections of the main stem and longitudinal sections of the shoot apical area showed the same patterns and intensity as the root (Fig. 3A to F).

In addition to these blue signals, infected phloem tissues showed characteristic internal symptoms. Phloem necrosis was first observed in root tissues at 28 dpi. Excessive phloem formation (hyperplasia) was also observed in the main stem at 28 dpi. Subsequently, external symptoms, such as stunted growth, became apparent (data not shown). No signals specific for OY phytoplasma were detected in healthy, uninfected control plants (Fig. 2D).
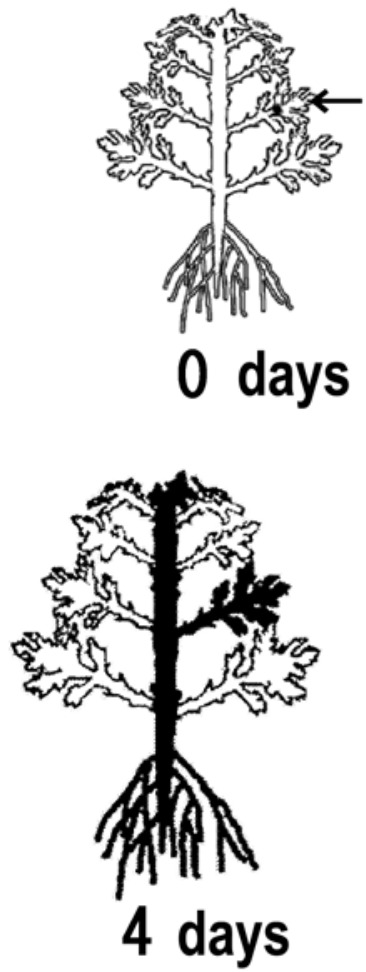

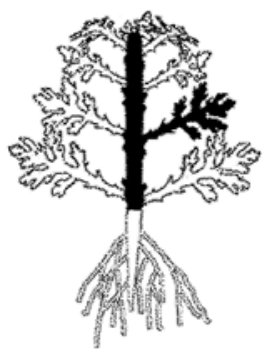

1 days

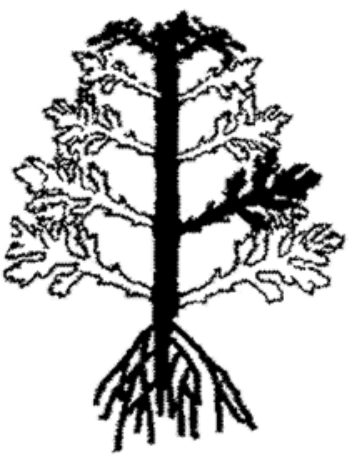

7 days

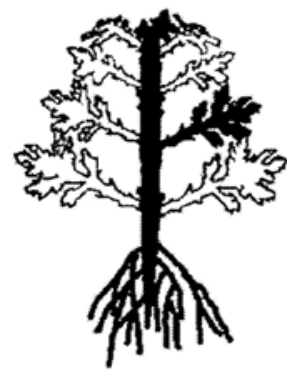

2 days

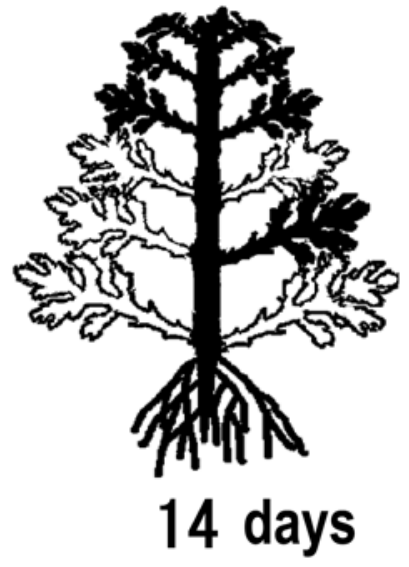

14 days

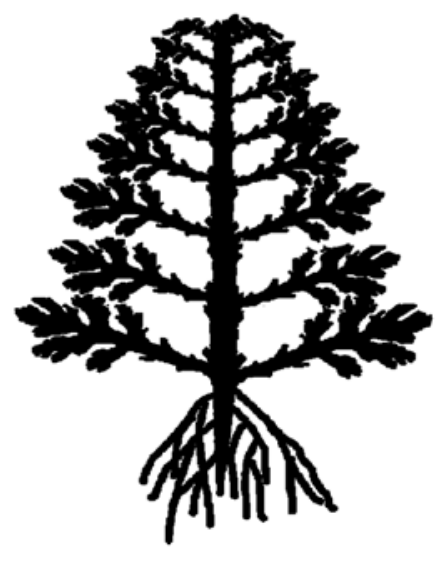

21 days

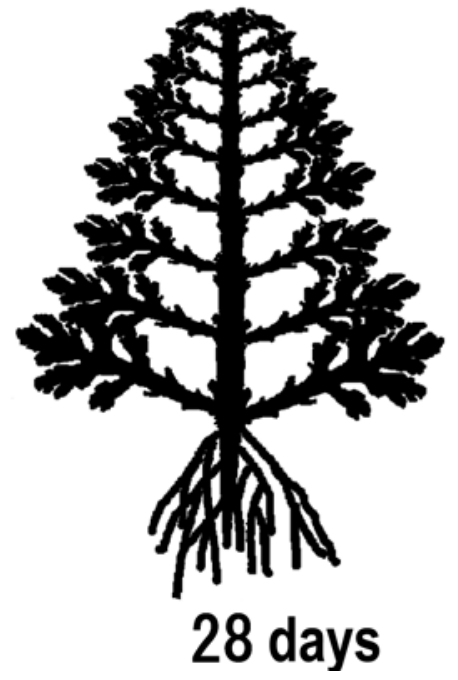

Fig. 4. Schematic representation of the proposed migration of onion yellows phytoplasma in garland chrysanthemum (Chrysanthemum coronarium). Filled areas denote phytoplasma localization. The arrowhead in 0 days denotes the inoculated site. 


\section{DISCUSSION}

Because plants cannot be inoculated mechanically with phytoplasma, it is very difficult to study the micro- and macrodynamics of phytoplasma localization and populations in host plants. To address this deficiency, we developed a localized inoculation technique and used nested PCR, real-time PCR, and immunohistochemical analysis. Localized inoculation via vector insects was effective for studying the dynamics of mechanically nontransmissible phytoplasmas.

Surprisingly, the nested PCR analysis revealed that OY phytoplasma migrated from the inoculated leaf into both the main stem and the apex very rapidly. Subsequently, phytoplasmas spread to both the root and the leaf at the top of the plant and then from the top of the plant to lower leaves. OY phytoplasmas were detected throughout the plant by $21 \mathrm{dpi}$ (Table 1 ). The immunohistochemical analysis provided firm evidence of the spread of OY throughout the phloem within 21 dpi (Figs. 2B and 3B and E). Therefore, systemic OY phytoplasma infection of garland chrysanthemum takes 3 weeks, and the OY phytoplasma population increases progressively following inoculation.

Based on these results, a model for the movement of OY phytoplasma in garland chrysanthemum following infection is proposed. The phytoplasma spreads sequentially from the inoculated leaf to the main stem, root, upper leaves, and then lower leaves (Fig. 4). On the other hand, distribution of the phytoplasma associated with Australian papaya dieback has been investigated by employing PCR. Phytoplasmas could be detected in the infected papaya tissues at different stages of disease progression, such as in the expanding leaves at an early infection stage and in the stem and roots when infected plants show obvious symptoms, while not at all in mature leaves at all stages of disease progression (21). Similarly, using ELISA and immunolocalization, grapevine flavescence dorée (FD) phytoplasma in Vicia faba was first detected in roots 17 days after inoculation and a large population of FD phytoplasma was in some sink regions, whereas the source organs showed passive accumulation (9). In this study, OY phytoplasma could be detected in all leaves at 21 days after inoculation via nested PCR. Nested or two-step PCR is much more sensitive than original PCR, and thus, the difference between this and the previous reports might be explained either by sensitivity of the methods used or by differences of the phytoplasma or the host plant used. Therefore, comparison in the future of in planta movement patterns of two different phytoplasmas in the same host plant or that of a single phytoplasma in the two different host plants should be informative.

The quantitative analysis of OY phytoplasma in inoculated garland chrysanthemums at various times postinoculation was carried out using real-time PCR. The OY phytoplasma was not detected by real-time PCR before $14 \mathrm{dpi}$, and the population increased about sixfold per week in the period from 14 to $28 \mathrm{dpi}$, suggesting that the OY phytoplasma population increases relatively slowly. PCR-based quantification of OY phytoplasma in leaves 4 weeks after inoculation indicated that phytoplasmas accumulate in the following order: the inoculated leaf and in the top leaf, upper leaves and then the lower leaves. These data support our proposed phytoplasma migration pattern in the garland chrysanthemum. Although it is not easy to accurately compare the population sizes of phytoplasmas in infected phloem among different plant parts (because the amount of phloem is not the same in different plant parts, even though the same weight of each part was sampled), we showed that the total phytoplasma population in roots was higher than that in leaves. This might be significant with respect to purification of phytoplasmas from plant tissues.

To our knowledge, this is the first report to describe the population dynamics and detailed in planta migration sequence of phytoplasmas using immunohistochemical analysis supported by nested PCR and real-time PCR. The observation of internal symptoms in phloem tissues from infected plants shows that immunohistochemical analysis is an effective tool for studying the histopathology of phytoplasma in a host plant. Application of our method to phytoplasma dynamics within insect vectors should provide novel insights into transportation and multiplication mechanisms. It also will be interesting to analyze the dynamics of the OY-M line, a mildly pathogenic mutant line of OY phytoplasma $(14,20)$, in the hope of revealing the biological basis for the mildness of OY-M.

\section{ACKNOWLEDGMENTS}

This work was supported partly by grants-in-aid from the Ministry of Education, Culture, Sports, Science and Technology of Japan (09460155 and 13306004) and by the program for Promotion of Basic Research Activities for Innovative Biosciences (PROBRAIN) of the Ministry of Agriculture, Forestry and Fisheries of Japan.

\section{LITERATURE CITED}

1. Clark, M. F., Barbara, D. J., and Davis, D. L. 1983. Production and characteristics of antisera to Spiroplasma citri and clover phyllodyassociated antigens derived from plants. Ann. Appl. Biol. 103:251-259.

2. Douglas, S. M. 1986. Detection of mycoplasma-like organisms in peach and chokecherry with X-diseases by fluorescence microscopy. Phytopathology 76:784-787.

3. Filion, M., St-Arnaud, M., and Jabaji-Hare, S. H. 2003. Direct quantification of fungal DNA from soil substrate using real-time PCR. J. Microbiol. Methods 53:67-76.

4. Jung, H.-Y., Hham, Y.-I., Lee, J.-T., Hibi, T., and Namba, S. 2003. Characterization of a phytoplasma associated with potato witches' broom disease in Korea. J. Gen. Plant Pathol. 69:87-89.

5. Kakizawa, S., Oshima, K., Kuboyama, T., Nishigawa, H., Jung, H.-Y., Sawayanagi, T., Tsuchizaki, T., Miyata, S., Ugaki, M., and Namba, S. 2001. Cloning and expression analysis of phytoplasma protein translocation genes. Mol. Plant-Microbe Interact. 14:1043-1050.

6. Kirkpatrick, B. C. 1987. Characterization of western X-disease mycoplasma-like organisms. Ph.D. thesis. University of California, Berkeley.

7. Kirkpatrick, B. C. 1992. Mycoplasma-like organisms: Plant and invertebrate pathogens. Pages 4050-4067 in: The Prokaryotes. 2nd ed. A. Balows, H. G. Truper, M. Dworkin, W. Harder, and K. H. Schleifer, eds. Springer-Verlag, New York.

8. Kuske, C. R., and Kirkpatrick, B. C. 1992. Distribution and multiplication of western aster yellows mycoplasma-like organisms in Catharanthus roseus was determined by DNA hybridization analysis. Phytopathology $82: 457-462$.

9. Lherminier, J., Courtois, M., and Caudwell, A. 1994. Determination of the distribution and multiplication sites of Flavescence Dorée mycoplasma-like organisms in the host plant Vicia faba by ELISA and immunocytochemistry. Physiol. Mol. Plant Pathol. 45:125-138.

10. McCoy, R. E., Caudwell, A., Chang, C. J., Chen, T. A., Chiykowski, L. N., Cousin, M. T., Dale De Leeuw, G. T. N., Golino, D. A., Hackett, K. J., Kirkpatrick, B. C., Marwitz, R., Petzold, H., Sinha, R. H., Sugiura, M., Whitcomb, R. F., Yang, I. L., Zhu, B. M., and Seemüller, E. 1989. Plant disease associated with mycoplasma-like organisms. Pages 546-640 in: The Mycoplasmas, vol. 5. R. F. Whitcomb and J. G. Tully, eds. Academic Press, New York.

11. Miyahara, K., Matsuzaki, M., Tanaka, K., and Sako, N. 1982. A new disease of onion caused by mycoplasma-like organism in Japan. Ann. Phytopathol. Soc. 48:551-554.

12. Miyata, S., Furuki, K., Sawayanagi, T., Oshima, K., Kuboyama, T., Tsuchizaki, T., Ugaki, M., and Namba, S. 2002. Gene arrangement and sequence of str operon of phytoplasma resemble those of Bacillus more than those of mycoplasma. J. Gen. Plant Pathol. 68:62-67.

13. Namba, S., Kato, S., Iwanami, S., Oyaizu, H., Shiozawa, H., and Tsuchizaki, T. 1993. Detection and differentiation of plant-pathogenic mycoplasma-like organisms using polymerase chain reaction. Phytopathology 83:786-791.

14. Nishigawa, H., Oshima, K., Miyata, S., Ugaki, M., and Namba, S. 2003. Complete set of extrachromosomal DNAs from three pathogenic lines of onion yellows phytoplasma and use of PCR to differentiate each line. J. Gen. Plant Pathol. 69:194-198.

15. Oshima, K., Shiomi, T., Kuboyama, T., Sawayanagi, T., Nishigawa, H., Kakizawa, T., Miyata, S., Ugaki, M., and Namba, S. 2001. Isolation and 
characterization of derivative lines of the onion yellows phytoplasma that do not cause stunting or phloem hyperplasia. Phytopathology 91:10241029.

16. Sawayanagi, T., Horikoshi, N., Kanehira, T., Shinohara, M., Bertaccini, A., Cousin, M.-T., Hiruki, C., and Namba, S. 1999. 'Candidatus Phytoplasma japonicum', a new phytoplasma taxon associated with Japanese Hydrangea phyllody. Int. J. Syst. Bacteriol. 47:1275-1285.

17. Schaff, D. A., Lee, I.-M., and Davis, R. E. 1992. Sensitive detection and identification of mycoplasma-like organism by polymerase chain reactions. Biochem. Biophys. Res. Commun. 186:1503-1509.

18. Schaper, U., and Seemüller, E. 1984. Recolonization of the stem of apple proliferation and pear decline diseased trees by the causal organisms in spring. Z. Pflanzenk. Pflanzen. 91:608-613.

19. Seemüller, E., Kunze, L., and Schaper, U. 1984. Colonization behavior of
MLO and symptom expression of proliferation-diseased apple trees and decline-diseased pear trees over period of several years. Z. Pflanzenk. Pflanzen. 91:525-532

20. Shiomi, T., Tanaka, M., Sawayanagi, T., Yamamoto, S., Tsuchizaki, T., and Namba, S. 1998. A symptomatic mutant of onion yellows phytoplasma derived from a greenhouse-maintained isolate. Ann. Phytopathol. Soc. 64:501-505.

21. Siddique, A. B. M., Gurthrie, J. N., Walsh, K. B., White, D. T., and Scott, P. T. 1998. Histopathology and within-plant distribution of the phytoplasma associated with Australian papaya dieback. Plant Dis. 82:11121120 .

22. Wei, W., Kawakita, H., and Sato, M. 2000. Detection of a small population of mulberry dwarf (MD)-phytoplasmas in symptomless-mulberry trees by nested PCR. J. Seric. Sci. Jpn. 69:261-269. 